\title{
Non-small-cell lung cancers: a heterogeneous set of diseases
}

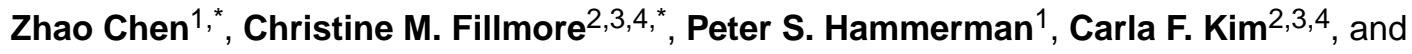 \\ Kwok-Kin Wong ${ }^{1,5,6}$ \\ ${ }^{1}$ Department of Medical Oncology, Dana-Farber Cancer Institute, Boston, Massachusetts 02115, \\ USA
}

2Stem Cell Program, Boston Children's Hospital, Boston, Massachusetts 02115, USA

${ }^{3}$ Harvard Stem Cell Institute, Cambridge, Massachusetts 02138, USA

${ }^{4}$ Department of Genetics, Harvard Medical School, Boston, Massachusetts 02115, USA

${ }^{5}$ Department of Medicine, Harvard Medical School, Boston, Massachusetts 02115, USA

${ }^{6}$ Belfer Institute for Applied Cancer Science, Dana-Farber Cancer Institute, Boston, Massachusetts 02115, USA

\begin{abstract}
Non-small-cell lung cancers (NSCLCs), the most common lung cancers, are known to have diverse pathological features. During the past decade, in-depth analyses of lung cancer genomes and signalling pathways have further defined NSCLCs as a group of distinct diseases with genetic and cellular heterogeneity. Consequently, an impressive list of potential therapeutic targets was unveiled, drastically altering the clinical evaluation and treatment of patients. Many targeted therapies have been developed with compelling clinical proofs of concept; however, treatment responses are typically short-lived. Further studies of the tumour microenvironment have uncovered new possible avenues to control this deadly disease, including immunotherapy.
\end{abstract}

Lung cancer results in the largest number of cancer-related deaths worldwide ${ }^{1,2}$. More than $85 \%$ of those cases are currently classified as non-small-cell lung cancer (NSCLC), for which the predicted 5-year survival rate is $15.9 \%$ - a figure that has only marginally improved during the past few decades ${ }^{3}$. Technological advances during the past decade, including the introduction of next-generation sequencing (NGS), the generation of multiple genetically engineered mouse models (GEMMs) of lung cancer and the construction of large databases characterizing the molecular features of human tumours, have transformed our view of NSCLC from histopathological descriptions to precise molecular and genetic identities that can be resolved to the single-cell level. In parallel, approaches and concepts from fields such as developmental biology, stem cell biology and immunology have deepened our knowledge of tumour development, cellular heterogeneity and interactions between the lung tumour and its surrounding microenvironment. These multidisciplinary

\footnotetext{
Correspondence to P.S.H., C.F.K. and K.-K.W. phammerman@partners.org; carla.kim@childrens.harvard.edu; kwong1@partners.org These authors contributed equally to this work.

Competing interests statement

The authors declare no competing interests.
} 
efforts have enhanced our understanding of molecular disease mechanisms, thereby forming the rationales for targeting different cellular compartments simultaneously. Scientists and physicians have better tools than ever to pursue answers to two provocative questions: first, how can we define the specific subsets of NSCLC that differ by cellular and molecular composition? Second, how can we effectively control lung cancer growth for each specific subset of NSCLC? In this Review, we discuss how data that are derived from technological advances in lung cancer genomics, mouse modelling of cancers and tumour microenvironment studies might be used to improve the survival of patients with NSCLC through the development of novel therapeutic strategies.

\section{Defining NSCLC subsets}

NSCLC is currently defined by pathological characteristics. The two predominant NSCLC histological phenotypes are adenocarcinoma (ADC; 50\%) and squamous cell carcinoma (SCC; $40 \%)^{4,5}$. In general, ADCs arise in more distal airways, whereas SCCs arise in more proximal airways and are more strongly associated with smoking and chronic inflammation than $\mathrm{ADCs}^{4,5}$. ADCs often have glandular histology and express biomarkers that are consistent with an origin in the distal lung, including thyroid transcription factor 1 (TTF1; also known as NKX2-1) and keratin 7 (KRT7) ${ }^{4,5}$. By contrast, SCCs are characterized by squamous differentiation, which is more reminiscent of the pseudostratified columnar epithelium that lines the trachea and upper airways ${ }^{4,6}$. SCCs are distinguished from ADCs in the clinic by immunostaining for cytokeratin 5 and cyto keratin 6 and/or the transcription factors SRY-box 2 (SOX2) and p63 (REFS 4,5,7). Other subtypes of NSCLC include large cell carcinoma, which is diagnosed by exclusion if tumour cells do not appear glandular or squamous in shape or express ADC or SCC biomarkers, although it is unclear whether large cell carcinomas are genetically distinct from $\mathrm{ADC}$ or $\mathrm{SCC}^{4}$. Some neuroendocrine tumours are also classified as NSCLC, although the most aggressive form of neuroendocrine tumour is classified as small-cell lung cancer (SCLC) ${ }^{4}$.

\section{Genetic mutations and genomic heterogeneity}

Although histological features and marker expression remain the basis of clinical tumour diagnosis, recent advances in NGS and other high-throughput genomic profiling platforms have allowed researchers to examine the breadth of genetic mutations within lung tumours. Following the identification of $K R A S$ and $B R A F$ mutations ${ }^{8,9}$, epidermal growth factor receptor $(E G F R)$ mutations were discovered in patients with lung ADC and were associated with response to EGFR inhibitors ${ }^{10-13}$. Further recurrent mutations and amplifications in many potentially targetable oncogenes have since been identified in lung ADC, including $H E R 2$ (also known as ERBB2), MET, fibroblast growth factor receptor $1(F G F R 1)$ and $F G F R 2$, as well as fusion oncogenes involving anaplastic lymphoma kinase $(A L K)$, the ROS1 receptor tyrosine kinase, neuregulin 1 (NRG1), neurotrophic tyrosine kinase receptor type 1 (NTRK1) and $R E T^{14-22}$. These oncogenic changes, many of which predict sensitivity to clinical inhibitors, jointly account for most cases of lung $\mathrm{ADC}^{23-25}$. For lung SCC, the number of tumours for which whole-exome sequencing is available is lower than for ADC but, so far, potentially targetable mutations in ADC do not seem to be prevalent in this histological subtype ${ }^{20}$. Instead, genes such as discoidin domain-containing receptor 2 
(DDR2), FGFR1, FGFR2, FGFR3 and genes in the PI3K pathway seem to be more commonly mutated in lung $\mathrm{SCC}^{20}$. Many of these mutations (with the exception of those in the PI3K pathway) have been validated by preclinical studies as driver mutations ${ }^{22,26,27}$.

NGS studies have also revealed the molecular taxonomy of lung cancer and have shown a dazzling complexity of somatic alterations in NSCLCs that extends far beyond protein kinases to include epigenome modifiers, transcription factors, splicing factors and genes involved in cellular immunity ${ }^{20,28,29}$. Potentially important mutations and copy number gains identified from patient tumours are summarized in TABLE 1, with relevant preclinical and clinical evidence. Among the 21 different tumour types for which exome sequences were directly compared, lung SCC and ADC ranked second and third highest in median somatic mutation frequency, with an average of ten mutations per megabase of coding DNA sequenced ${ }^{30}$. It is worth noting that ADCs in non-smokers have 5-6-times fewer mutations ${ }^{24,31}$. Given this relatively large number of mutations per tumour, there will probably be more important mutations identified for NSCLC as the number of tumours that are analysed increases. An important challenge that remains is understanding which of these many mutations are important in lung carcinogenesis and/or treatment response, in contrast to those mutations that are merely a consequence of the tumorigenic process. Thus, the genomic profiles highlight the heterogeneity of the NSCLC genome and provide a plausible explanation for the highly heterogeneous treatment responses that we have observed in the clinic. By cataloguing a large collection of mutations for each patient, a more accurate evaluation of the net effects of genotype and therapy response may be achieved and will ultimately inform the most suitable treatment strategies.

Other novel technologies have also facilitated the discovery and validation of somatic mutations in lung cancer. For example, high-throughput screens using established short hairpin RNA (shRNA) libraries have identified genes that cause synthetic lethality with common oncogenic events, such as KRAS-activating mutations or p53 inactivation, leading to potential new treatment targets, such as TANK-binding kinase 1 (TBK1) ${ }^{32}$. Similarly, the application of mass spectrometry to metabolomic, proteomic and phosphokinase profiling, as well as single cell time-of-flight mass cytometry (cyTOF), have led to numerous new findings, including the discovery of recurrent aberrations such as the ROS1 fusions and the potential diagnostic or prognostic marker isocitrate dehydrogenase 1 (IDH1) ${ }^{17,33,34}$. Such advances in high-throughput technology are promoting rapid advances in our understanding of NSCLC biology and, ultimately, will help to determine how NSCLC develops, spreads and can be better treated.

\section{Heterogeneity in lung tumour microenvironments}

The concept of tumour heterogeneity applies not only to tumour epithelial cells but also to the diverse microenvironments with which the tumour cells interact ${ }^{35}$. Carcinoma cells, in the lung and other organs, are closely associated with the extracellular matrix (ECM), mesenchymal cells such as fibroblasts, infiltrating immune cells and vasculature (FIG. 1). In some cases, this environment is essential to tumour initiation or tumour growth, whereas in other cases it can prevent tumorigenesis or even promote tumour clearance 35,36 . 
In lung tumorigenesis, genesis of new blood and lymphatic vessels supplies necessary nutrients for tumour growth and allows for an influx of immune cells of the myeloid and lymphoid lineages. The myeloid cells that are implicated in this process include tumourassociated macrophages (TAMs) and tumour-associated neutrophils ${ }^{37}$. Mice that harboured germline knock-in of kinase-dead inhibitor of nuclear factor- $\kappa \mathrm{B}(\mathrm{NF}-\kappa \mathrm{B})$ kinase subunit-a (IKKa) developed spontaneous lung SCC that is characterized by NF- $\kappa B$ activation and marked accumulation of TAMs that were essential for disease progression ${ }^{38}$. Secretion of pro-angiogenic factors such as platelet-derived growth factor (PDGF) and vascular endothelial growth factor (VEGF) by TAMs in lung cancer suggests why these cells are associated with increased microvessel formation ${ }^{39,40}$. Likewise, increased neutrophil numbers have been associated with poor prognosis in NSCLCs, perhaps owing to their ability to degrade matrices with elastase $\mathrm{e}^{41,42}$. Neutrophils that are found in mouse tumours are phenotypically characterized as polymorphonuclear CD11B- and lymphocyte antigen $6 \mathrm{G}$-expressing $\left(\mathrm{CD} 11 \mathrm{~B}^{+} \mathrm{Ly} 6 \mathrm{G}^{+}\right)$cells, and are often considered to be a subtype of myeloid-derived suppressor cells (MDSCs) ${ }^{43}$. In the tumour microenvironment, accumulated MDSCs are thought to promote tumour progression by increasing matrix degradation, tumour cell proliferation, metastasis and angiogenesis ${ }^{35,37}$.

Tumours can evade immune surveillance by expressing molecules that maintain tolerance to normal peripheral tissues, including the interaction of the tumour-associated programmed cell death 1 ligand 1 (PDL1) with the immune receptor programmed cell death 1 (PD1; also known as PDCD1). Recently, the use of antibodies targeting the PD1-PDL1 checkpoint has resulted in some marked responses in early-stage clinical trials for a large panel of therapyrefractory cancer subtypes, including advanced melanoma, NSCLC and renal cell cancer, with a proportion of responding patients showing persistent long-term benefits ${ }^{44,45}$. The PD1-PDL1 interaction inhibits $\mathrm{CD} 8^{+}$cytotoxic T lymphocyte proliferation, survival and effector function, and can induce apoptosis of tumour-infiltrating T cells; PD1-PDL1 interactions can also promote the differentiation of $\mathrm{CD}^{+} \mathrm{T}$ cells into forkhead box P3expressing $\left(\mathrm{FOXP}^{+}\right)$regulatory $\mathrm{T}\left(\mathrm{T}_{\mathrm{Reg}}\right)$ cells, which are known to further suppress the immune system and cause peripheral immune tolerance in patients with lung cancer ${ }^{46}$. Despite the promising clinical benefits, there is currently no defined subset of patients with lung cancer who are particularly sensitive to PD1-PDL1 blockade. This is partly due to a lack in the understanding of how tumour cells affect their microenvironment, including the surrounding immune cells $\mathrm{s}^{4,45,47}$. Evaluating the expression of PDL1 on tumour cells is only the starting point in the analysis of the interactions between tumour cells and the surrounding microenvironment ${ }^{48,49}$. Many important questions remain, including whether lung tumours with distinct genetic backgrounds differ in how they shape their immune microenvironment.

Differences in the ability to secrete inflammatory cytokines such as interleukin-6 (IL-6) may be one way in which tumour cells influence their surroundings ${ }^{50,51}$. Tumours that are driven by different oncogenic mutations in mice, such as EGFR and Kras, have distinguishable immune infiltrates with respect to cell types and their phenotypes in the tumour immune microenvironment ${ }^{48,49}$. These mechanisms have not been defined in detail, and there are other important questions to consider: does each genetic subset of NSCLC have its own 
unique microenvironmental influences, or can common characteristics of how the surroundings drive tumour subsets be uncovered? How does targeted therapy alter the tumour microenvironment? Do drug-resistant or recurrent tumours have an environmental milieu that is distinct from the initial untreated tumour? A more thorough understanding of these dynamic interactions will help to show new targets that can be manipulated to promote antitumor effects. Importantly, many of these questions are challenging to understand, given the need to study the immune system in vivo, and the use of mouse models with intact immune systems in combination with patient samples may be instructive.

\section{Cell(s) of origin for NSCLC heterogeneity at tumour initiation}

Another contributing factor to the diversity of NSCLCs may be the potential distinct cells of origin in which subsets of NSCLC first arise. The cell of origin for each subset of NSCLC is essentially unknown beyond initial work in this area in mouse models. For example, it remains to be understood whether multiple cell types are equally likely to produce $K R A S$ mutant ADC or if only one cell type exists in the right microenvironment and must gain oncogenic $K R A S$ expression to produce this type of ADC. It is possible that the biology of different cells of origin is what drives the different phenotypes of NSCLCs with distinct genotypes. This could be the result of unique gene expression patterns of the originating cells, differences in the type of cells that the originating cells can produce, or unique microenvironments of the originating cell type. Ultimately, the clinical importance behind these seemingly basic biological questions is whether a different cell of origin partly dictates treatment responses. Can knowledge of the cell of origin predict environmental influences that can be targeted for antitumour therapy? Furthermore, can knowledge of the cell of origin be used for the earlier detection of tumours? The answers to these questions have the capacity to revolutionize our current concept of the stratification, diagnosis and treatment of NSCLC.

A long-standing hypothesis proposes that stem and progenitor cells in adult tissues function as carcinoma cells of origin because they are the only cells that have a sufficient lifespan to accumulate the many genetic alterations required for tumour progression ${ }^{52}$. Furthermore, stem cells have inherent self-renewal capacity and may not need extensive epigenetic reprogramming. However, even genetically normal cells with limited self-renewal capacity can be induced to acquire more stem cell-like properties in response to genetic alterations or microenvironmental changes ${ }^{53,54}$, and this supports the idea that more mature, differentiated cells may be just as likely to give rise to malignancy. Historically, ADCs have been proposed to arise from club cells (previously known as Clara cells) or alveolar epithelial type 2 (AT2) cells, owing to the staining of patient ADCs by immunohisto chemistry with markers of these cell types ${ }^{4,5}$. However, it is important to note that the staining pattern of a tumour is merely a snapshot of the gene expression of the tumour cells at that time point and might not match the initiating cell type. Our current understanding of cells of origin for lung cancer is mostly derived from experimental data using GEMMs ${ }^{55}$ (BOX 1; FIG. 2). Many conditional GEMMs target activation and/or loss of genes specifically to lung cells by intranasal or intratracheal instillation of adenovirus-Cre, which infects lung epithelial cells along the proximal to distal tract. After using intra nasal adenovirus-Cre to induce oncogenic Kras, loss of Pten or loss of $p 38$, the first hyperproliferative cells to be observed were 
bronchioalveolar stem cells (BASCs) - implicating them as possible ADC cells of origin $^{56-58}$. However, in more recent studies that targeted the expression of oncogenic $\mathrm{Kras}^{G 12 D}$ only in cells expressing club cell secretory protein (CCSP), such as club cells and BASCs, or only in cells expressing surfactant protein C (SPC), such as AT2 cells and BASCs, AT2 cells seemed to be the only cells that were capable of giving rise to advanced ADC in the alveolar space, whereas club cells and BASCs seemed to be limited to driving bronchiolar hyperplasia within the same time frame ${ }^{59}$. Using these approaches, it is notable that changes in the cells of origin were evident when the genotype for tumour initiation was altered (for example, to include p53 loss) or if injury or inflammation were present during tumour initiation (for example, after adenovirus infection or after naphthalene-induced injury $)^{56,59-63}$. Injury or inflammation probably more closely mimics the scenario of tumour initiation in humans, in which environmental influences and ongoing injury occur in contrast to the relatively sterile mouse colony. These questions are unexplored in other models of ADC that use distinct oncogenes or in SCC. Thus, it remains entirely possible that club cells, AT2 cells and BASCs are all possible initiators of lung ADC. Future development of more precise lineage-specific Cre drivers combined with approaches to study tumorigenesis in the context of injury and inflammation (situations that are more likely to mimic carcinogenesis in humans) will be needed to better determine the comparable ADC-initiating activity of these populations.

Although increasing amounts of genomic data show that distinct gene expression programmes and driver mutations distinguish ADC from SCC, it remains unclear whether these two tumour types arise from a common cell of origin or diverse cell types, including different lung stem or progenitor cells (BOX 2). Until recently, a paucity of GEMMs for SCC has precluded analysis of the cells of origin of this important NSCLC subtype. It has long been hypothesized that SCC arises from basal cells, as lung SCCs most frequently arise in the proximal lung ${ }^{4}$, but also because they often express KRT5, SOX2 and p63, which are markers of the normal basal cell population ${ }^{5-7,62,64}$. GEMMs of ADC have been more widespread, mostly owing to the usefulness and availability of the conditional oncogenic Kras allele (which drives lung ADCs both independently and more rapidly in combination with $\operatorname{Trp} 53$ loss) as well as early models using chemicals that induce RAS mutations to drive tumours. Although $K R A S$ or $N R A S$ mutations are present in up to $25 \%$ of ADCs, they are rarely detected in SCCs, and mouse modelling with these oncogenes seems to result predominantly in the development of ADC. Mutations that are common in samples from patients with SCC have only recently been catalogued, and this opens up new ideas about how to model SCC ${ }^{20}$. Kinase-dead IKKa knock-in mice develop spontaneous lung SCC, but because this mouse has a germline Ikka mutation, it is not clear which cells in the lung expanded into the squamous tumours ${ }^{38}$. Loss of the tumour suppressor liver kinase B1 ( $L k b 1$; also known as Stk11) in the oncogenic $\mathrm{Kras}^{G 12 D}$ model produces a mixture of tumours, including ADC, SCC and large cell carcinoma ${ }^{65}$. Similarly, a mixture of ADC and SCC is found in mice after targeted deletion of Pten or transforming growth factor- $\beta$ receptor $2(\mathrm{Tgfbr} 2)$ in proximal cells with keratin-driven Cre alleles in the $\mathrm{Kras}^{G 12 D}$ background $^{66}$. Expression of the transcription factor Sox 2 (overexpressed in 20-60\% of human SCCs) in club cells and BASCs produces lung tumours that express the marker p63 but histologically resemble $\mathrm{ADCs}^{7}$. This intriguing finding suggests that distal lung epithelia 
are unable to produce a fully squamous phenotype, despite the expression of an SCC transcription factor. In addition, the deletion of $L k b 1$ and Pten in the lung via intranasal adenovirus-Cre was recently shown to give rise to fully penetrant lung SCCs ${ }^{49}$. The next important step will be to use lineage-restricted Cre alleles, such as the oestrogen-responsive Cre under control of the Krt5 promoter (Krt5-Cre-ER), to determine which lung cells that are null for $L k b 1$ and Pten are able to drive squamous disease.

\section{Tumour-propagating cells (TPCs) and cellular plasticity: heterogeneity between tumour cells}

'Cancer stem cells' or TPCs, which are defined as the tumour cells with the stem cellproperties of self-renewal and differentiation, have the capacity to produce tumours in transplantation assays. Establishment of tumours at metastatic sites and tumour recurrence following treatment have been attributed to growth and survival of TPCs ${ }^{67,68}$. Recent studies have identified potential cell surface markers or genetic traits that may mark the TPC population in NSCLC, such as aldehyde dehydrogenase (ALDH) activity or expression of NOTCH, CD24, CD166 or CD44 (REFS 38,69-73). However, these studies have not used serial transplant assays in the context of the lung environment, and a bona fide human lung TPC remains to be defined. GEMMs have allowed for more systematic study of lung TPC phenotypes, including serially transplanted tumours and metastases. Studies in the

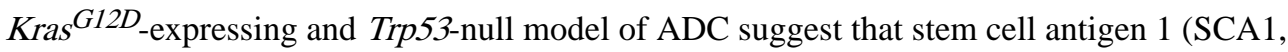
also known as Ly6A) $)^{+}, \mathrm{CD} 24^{+}, \beta 4$ integrin $^{+}$, and NOTCH3 3 hi mark the TPC population ${ }^{70,73}$. The identity of TPCs from other ADC GEMMs is unknown; SCA1 did not enrich for TPCs from the Kras- or EGFR-driven GEMMs ${ }^{74}$. In the first lung-specific genetic model of SCC (the Lkb1-and Pten-null model) the TPCs had a high expression of SCA1 and the basal cell marker nerve growth factor receptor (NGFR). Intriguingly, these TPCs also expressed high levels of the immune-checkpoint molecule PDL1, which may be targetable as described above $^{49}$. Overall, these findings indicate the importance of taking the genotype of the tumour into account when seeking to define a TPC population; each subset of NSCLC might harbour TPCs with unique surface markers and molecular drivers, which could each be uniquely targeted. Alternatively, many subsets of NSCLC might not have one TPC population that can be defined. Future research focusing on resolving the metastatic activity and therapy response of murine TPCs and the molecules that control them may help to translate these findings to improve the treatment of patients with lung cancer.

The genetic complexity and rapid clonal evolution of lung tumours could mean that if TPCs do occur in most lung cancers, they will have a high degree of plasticity. Fascinating clinical observations have shown some patients who are initially diagnosed with EGFR-driven ADCs develop SCLC after long-term treatment with the EGFR tyrosine kinase inhibitors gefitinib or erlotinib ${ }^{75,76}$. In contrast to ADC models, lineage tracing and viruses that are engineered to express Cre under the control of various cell-type-specific promoters have been used to show that SCLCs probably arise from neuroendocrine cells ${ }^{76-78}$. However, examination of these tumours before and after SCLC conversion shows the persistence of the same EGFR mutations, suggesting a shared clonal origin of both types of tumours. This highlights the potential epigenetic plasticity of lung cells and lung tumours after therapy ${ }^{75}$. Further careful evaluation of TPC activity and cellular plasticity of tumour cells with patient 
tissues, probably using patient-derived xenograft (PDX) models and GEMMs of lung cancer, will help us to better understand tumour lineage conversion as a path towards developing chronic treatment resistance. These findings also highlight the importance of considering how cells of origin may differ, depending on the therapeutic status of the tumour environment.

\section{Integrated therapies for NSCLC}

\section{Target validation and patient stratification}

Although studies of lung cancer genomes have implicated several genes as likely crucial mediators of tumour initiation and progression, experimental validation of the most important, functional genomic changes in lung cancer cells remains a challenge. Despite computational approaches to separate 'driver' alterations from passenger alterations, this distinction is probably more nuanced, and substantial work will need to be completed to model the consequences of specific genome alterations in NSCLC. Existing repositories of lung cancer cell lines, as well as efforts to generate new cell lines from patient tumours have led to a number of important discoveries, although these cell lines still fail to represent the full diversity of human NSCLCs ${ }^{79}$. Three-dimensional culture techniques might also offer a new way to propagate normal and tumorigenic lung cells to better probe vulnerabilities of tumour cells ${ }^{49,73}$. Multiple in vivo models using mice to recapitulate lung cancer disease processes and treatment responses have been generated, including GEMMs harbouring specific genetic aberrations that have been identified in human tumours ${ }^{55,80}$ (BOX 1). Translation of the experimental results obtained through in vitro and in vivo modelling systems has formed the basis for current and future patient stratification paradigms (BOX 3). The limitations of these approaches should also be considered in future work to develop a more precise understanding of how to predict therapy response.

\section{Current treatments for NSCLC}

The past decade has seen some truly impressive new treatments for subsets of patients with lung cancer, most of whom harbour mutations in one of the key oncogenic driver mutants upon which tumour survival and progression are dependent. These include mutations in $E G F R$, the echinoderm microtubule-associated protein-like 4 (EML4)-ALK fusion and ROS1 fusions ${ }^{81,82}$. Extensive preclinical and clinical studies have proven the marked treatment responses and survival advantages over conventional chemotherapies that are provided by target-specific inhibitors to EGFR-activating mutations or to ALK fusions ${ }^{83-85}$. Recent genomic analyses of lung SCC have also given the first set of potentially targetable driver mutations, including FGFR1, FGFR2, FGFR3, DDR2 and PI3K ${ }^{20}$. Clinical trials that aim to target these subsets of patients who have Stage I-IIIA lung cancers are currently underway; preliminary results were presented at the 2014 American Association for Cancer Research Annual Meeting ${ }^{86}$, and these showed responses to an FGFR inhibitor (BGJ398) in a subset of patients with SCC who have FGFR 1 amplification.

Unfortunately, acquired resistance to chronic treatment often develops within 9-12 months in most patients who are treated with kinase inhibitors ${ }^{84,87,88}$. Therefore, patients who have Stage I-IIIA tumours are still treated by surgical resection as a first-line treatment and 
receive combination chemotherapy as a standard of care, with the use of targeted agents still considered to be experimental. For patients with advanced disease who have progressed on an inhibitor of EGFR or ALK, several recurrent secondary mutations have been identified, such as EGFR-T790M and additional kinase domain mutations in $\mathrm{ALK}^{87,88}$. Hence, finding treatments for tumours that are resistant to first-generation EGFR or ALK inhibitors has been a recent focus. Several newly developed inhibitors that either have more potency or are rationally designed to favourably target the mutated kinases, such as AZD9291 and CO-1686 for EGFR and LDK378 for EML4-ALK, have generated promising initial clinical results ${ }^{89-91}$. Discovery of the mechanisms that underlie acquired resistance in patients without additional mutations in the primary driver gene is also greatly facilitated by highthroughput analytical approaches. Amplifications of $A L K$ and alternative pro-cancerous pathway activations were identified in $A L K$ fusion-positive patients who have become resistant to the first-generation ALK inhibitor crizotinib ${ }^{87}$. In patients who are resistant to chronic EGFR inhibitor treatment, a wide range of resistance mechanisms has been reported. These include increased activities of additional kinases owing to MET, HER2 or ERK amplification, additional mutation of PIK3CA (which encodes the PI3K p110a subunit) or overexpression of AXL kinase ${ }^{14,92-95}$. Enhanced NF- $\kappa B$ signalling activity was also implied as one possible resistance mechanism that is evident by an improved response and survival in patients with EGFR mutations who have an increased expression of the NF- $\kappa B$ inhibitor I $\mathrm{KBa}$ (also known as NFKBIA) ${ }^{96}$. In addition, a common BIM (also known as BCL2L11) polymorphism that results in changes in splicing and the deletion of the pro-apoptotic BCL-2-homology domain (BH3) was shown to potentially mediate intrinsic resistance to EGFR inhibitors ${ }^{97}$, highlighting the complexity of possible resistance mechanisms. It is conceivable that the comprehensive acquisition of information on different aspects of tumour biology, such as genomic and kinase profiling in patients, will be crucial in the future to determine the best course of treatment following any new diagnosis or the development of acquired resistance.

Most patients with advanced stage NSCLC without targetable genomic alterations are still treated by conventional chemotherapies. Activating KRAS mutations were identified and verified long before the discovery of mutant EGFR. However, treatment choices for patients with KRAS-mutant lung cancer are still very limited. Current efforts to treat this subset of patients have been mostly focused on inhibiting common KRAS downstream signalling cascades. The RAF-MEK-ERK pathway, which is activated directly downstream of KRAS, has proven to be a valid target in both preclinical models and clinical trials ${ }^{98-100}$. However, the clinical benefits of MEK inhibitors, even in combination with other agents, are still somewhat moderate compared to those of target-specific inhibitors such as erlotinib for patients with activating EGFR mutations, and the use of MEK inhibitors is associated with additional complications and enhanced toxicity ${ }^{100}$. The available preclinical and clinical results present clear challenges to the common belief that therapies targeting one or a few specific alterations should have fewer side effects and lower toxicity compared to standard chemotherapies. Indeed, this is not entirely a surprise, as many of the targeted pathways for lung cancer treatment are also essential for normal tissue functions. The simultaneous inhibition of multiple signalling pathways can be deleterious to necessary normal cells. One possible remedy being explored is to optimize treatment schedules and improve targeting 
efficiencies for single-pathway inhibition by improving inhibitor potency or linear inhibition of multiple targets within the pathway. Nonetheless, alternative treatment approaches with less toxicity and better responses are of immediate need. A few studies have more recently reported the rational design of KRAS inhibitors that target the cysteine residue of the common KRAS mutation $\mathrm{G} 12 \mathrm{C}$ in lung cancer ${ }^{101,102}$, and these are therefore similar to the second-generation EGFR inhibitors (such as WZ4002, AZD9291 and CO-1686) that target EGFR-T790M. In vitro studies of these KRAS inhibitors demonstrate a proof of concept ${ }^{101,102}$; however, the in vivo efficacy of these molecules still requires much more investigation.

\section{Targeting multiple cellular compartments in lung cancer}

Similar to KRAS mutations, many newly identified potential pro-cancerous changes, such as overexpression of the transcription factors SOX2 and $\mathrm{MYC}^{103-105}$, present clear challenges to our current ideas about treatment approaches - in cases in which there is no clear druggable target, what can be done? Furthermore, the short-lived in vivo efficacy for most if not all existing small molecule inhibitors ${ }^{87,106}$ also advocates more durable treatment approaches. On the basis of our current understanding, the more effective approach probably requires therapies that not only target tumour cells but also target other components of the tumour, such as tumour vasculature, tumour-associated fibroblasts and tumour-specific and/or non-specific immune cells. Besides the more recently studied PD1-PDL1 inhibitory pathway, other approaches that intervene with the immune system, such as antibodies against cytotoxic T lymphocyte protein 4 (CTLA4; also known as CD152), CD73 or CD47, and more sophisticated cellular immune therapies, such as engineered $\mathrm{T}$ cell therapy using chimeric antigen receptors (CARs), are also under extensive scrutiny ${ }^{107-110}$. More importantly, ongoing efforts are seeking to discover the best combination approach that integrates immune therapy with other therapies. Angiogenesis has long been seen as a possible therapeutic window, with many novel therapeutic agents that have been developed or are being developed to clinically target this process, although the overall efficacy of anti-angiogenic agents has been modest in unselected patient cohorts ${ }^{111}$. Emerging evidence has suggested that the combination of immunotherapy and anti-angiogenic agents has potential synergistic effects ${ }^{112,113}$, pointing to a new possible avenue to mutually enhance both treatments. In addition to providing key nutrients and oxygenated blood, tumour vasculature might have a role in supporting TPCs ${ }^{35,114}$. Similarly, stromal cells such as fibroblasts have been shown to provide additional signals that support tumour growth and survival, and they may therefore have major roles in primary and acquired treatment resistance ${ }^{35,115}$. Understanding how best to target these various aspects of the tumour microenvironment would require a high-throughput comparison of changes in the tumour microenvironment that occur upon single and combination treatments.

Targeted therapies might also be able to indirectly regulate tumour growth. Two prominent examples are drugs that target epigenetic enzymes and metabolic enzymes. Targeting epigenetic enzymes is expected to enable marked perturbation of gene expression within tumour cells to stop tumour growth. The recently developed bromodomain protein inhibitors have shown efficacy in numerous preclinical studies ${ }^{116}$, including in lung cancer ${ }^{117}$, and they are currently under evaluation in the clinic, including in the ongoing Phase I clinical 
trials NCT01987362 and NCT01587703. Variations in expression as well as recurrent mutations were also reported for several histone- and DNA-modifying enzymes, including enhancer of zeste homologue 2 (EZH2), TET methyl cytosine dioxygenase 2 (TET2) and DNA methyltransferase 3A (DNMT3A) in all subtypes of NSCLC ${ }^{28}$. In a similar concept, altered metabolism is one of the key features of cancer cells. Anti-diabetic drugs, insulinlike growth factor 1 receptor (IGF1R) inhibitors and drugs that target glycolysis or lipid, nucleic acid and amino acid synthesis are currently being explored for anti tumour activities in NSCLC ${ }^{118-121}$. Targeting metabolism is certainly promising for cancer control, particularly when combined with other approaches. Recent studies have also highlighted connections between TET and IDH, which could have resulted in a $\mathrm{CpG}$ island methylator phenotype (CIMP) in a subset of lung cancer, and this 'connects the dots' between epigenetics and metabolism ${ }^{122-124}$.

\section{Conclusion}

The quickened pace of discovery of mechanisms that underlie lung cancer development and possible treatments in the past decade present the opportunity to integrate information from multiple approaches for future lung cancer treatment. Large amounts of information about the identity of individual lung tumours are being collected. New and improved functional studies are needed to meet the pace of data set generation, and all of the aspects of tumour heterogeneity - genetic, cellular and epigenetic — need to be integrated to determine better approaches to make an impact in this devastating disease. We anticipate the future treatment scheme to be a genotype-dependent, carefully selected combination that would ensure an enhanced tumour immune reaction, inhibition of angiogenesis and blockade of interactions between tumour cells and stromal cells. Thus, we advocate 'integrated therapy', in contrast to the current concept of targeted therapy, as the future of effective NSCLC treatment.

\section{Acknowledgments}

The authors thank United Against Lung Cancer, Thoracic Foundation, Bonnie J Addario Lung Cancer Foundation, Claudia Adams Barr Program For Basic Cancer Research, grant numbers CA122794, CA166480, CA163896, CA154303, CA120964 CA140594.

\section{Glossary}

\section{Myeloid-derived suppressor cells (MDSCs)}

MDSCs encompass a heterogeneous population of myeloid cells, which share the ability to suppress $\mathrm{T}$ cells through the production of arginase and the expression of inducible nitric oxide synthase (iNOS)

\section{Pseudostratified epithelium}

This describes the epithelium of the trachea, which is truly a monolayer but appears to have some stratification due to the variable distances of the nuclei from the basal lamina

\section{Patient-derived xenograft (PDX)}

Primary tumour cells from fresh patient tumours that are propagated subcutaneously in immunocompromised mice 


\section{EGFR-T790M}

The most common mutation ( $\sim 50 \%)$ in the epidermal growth factor receptor $(E G F R)$ gene that confers resistance to EGFR tyrosine kinase inhibitors such as erlotinib and gefitinib

\section{Cytotoxic T lymphocyte protein 4}

(CTLA4; also known as CD152). A surface receptor that transmits inhibitory signals to T cells.

CD73

A cell surface enzyme that generates extracellular adenosine, which inhibits $\mathrm{T}$ cell function

\section{CD47}

The receptor for thrombospondin 1 (TSP1). CD47 is highly expressed in many tumour cells

\section{Chimeric antigen receptors}

(CARs). Genetically engineered receptors that result in desired specificity (to tumour cells) in effector T cells

\section{CpG island methylator phenotype}

(CIMP). Reflects the genomic status that multiple $\mathrm{CpG}$ islands are methylated simultaneously, leading to epigenetic inactivation of different genes, including tumour suppressors

\section{References}

1. Jemal A, et al. Global cancer statistics. CA Cancer J Clin. 2011; 61:69-90. [PubMed: 21296855]

2. Siegel R, Naishadham D, Jemal A. Cancer statistics, 2013. CA Cancer J Clin. 2013; 63:11-30. [PubMed: 23335087]

3. Ettinger DS, et al. Non-Small Cell Lung Cancer, Version 2.2013. J Natl Compr Canc Netw. 2013; 11:645-653.

4. Davidson MR, Gazdar AF, Clarke BE. The pivotal role of pathology in the management of lung cancer. J Thorac Dis. 2013; 5:S463-S478. [PubMed: 24163740]

5. Langer CJ, Besse B, Gualberto A, Brambilla E, Soria JC. The evolving role of histology in the management of advanced non-small-cell lung cancer. J Clin Oncol. 2010; 28:5311-5320. [PubMed: 21079145]

6. Rock JR, Randell SH, Hogan BLM. Airway basal stem cells: a perspective on their roles in epithelial homeostasis and remodeling. Dis Model Mech. 2010; 3:545-556. [PubMed: 20699479]

7. Lu Y, et al. Evidence that Sox 2 overexpression is oncogenic in the lung. PLoS ONE. 2010; 5 http:// dx.doi.org/10.1371/journal.pone.0011022.

8. Davies H, et al. Mutations of the $B R A F$ gene in human cancer. Nature. 2002; 417:949-954. [PubMed: 12068308]

9. Santos E, et al. Malignant activation of a K-ras oncogene in lung carcinoma but not in normal tissue of the same patient. Science. 1984; 223:661-664. [PubMed: 6695174]

10. Lynch TJ, et al. Activating mutations in the epidermal growth factor receptor underlying responsiveness of non-small-cell lung cancer to gefitinib. N Engl J Med. 2004; 350:2129-2139. [PubMed: 15118073]

11. Paez JG, et al. EGFR mutations in lung cancer: correlation with clinical response to gefitinib therapy. Science. 2004; 304:1497-1500. In this study, the clinical observation that only some lung cancers responded well to the EGFR inhibitor gefitinib was linked to the presence of EGFRactivating mutations in the responding tumours. This finding revolutionized the stratification of 
patients that receive EGFR inhibitor treatment and furthered our understanding of oncogene addiction in NSCLC. [PubMed: 15118125]

12. Pao W, et al. EGF receptor gene mutations are common in lung cancers from "never smokers" and are associated with sensitivity of tumors to gefitinib and erlotinib. Proc Natl Acad Sci USA. 2004; 101:13306-13311. [PubMed: 15329413]

13. Shepherd FA, et al. Erlotinib in previously treated non-small-cell lung cancer. N Engl J Med. 2005; 353:123-132. [PubMed: 16014882]

14. Engelman JA, et al. MET amplification leads to gefitinib resistance in lung cancer by activating ERBB3 signaling. Science. 2007; 316:1039-1043. [PubMed: 17463250]

15. Fernandez-Cuesta L, et al. CD74-NRG1 fusions in lung adenocarcinoma. Cancer Discov. 2014; 4:415-422. [PubMed: 24469108]

16. Kohno T, et al. KIF5B-RET fusions in lung adenocarcinoma. Nature Med. 2012; 18:375-377. [PubMed: 22327624]

17. Rikova K, et al. Global survey of phosphotyrosine signaling identifies oncogenic kinases in lung cancer. Cell. 2007; 131:1190-1203. [PubMed: 18083107]

18. Soda M, et al. Identification of the transforming $E M L 4-A L K$ fusion gene in non-small-cell lung cancer. Nature. 2007; 448:561-566. [PubMed: 17625570]

19. Stephens P, et al. Lung cancer: intragenic ERBB2 kinase mutations in tumours. Nature. 2004; 431:525-526.

20. The Cancer Genome Atlas Research Network (TCGA). Comprehensive genomic characterization of squamous cell lung cancers. Nature. 2012; 489:519-525. As part of The Cancer Genome Atlas, this study was the first to provide a comprehensive landscape of genomic and epigenomic alterations in lung SCCs. This study identified potential druggable targets in most tumours, and many of these targets are now being validated as therapeutic options. [PubMed: 22960745]

21. Vaishnavi A, et al. Oncogenic and drug-sensitive NTRK1 rearrangements in lung cancer. Nature Med. 2013; 19:1469-1472. [PubMed: 24162815]

22. Weiss J, et al. Frequent and focal FGFR 1 amplification associates with therapeutically tractable FGFR1 dependency in squamous cell lung cancer. Sci Transl Med. 2010; 2:62ra93.

23. Ding L, et al. Somatic mutations affect key pathways in lung adenocarcinoma. Nature. 2008; 455:1069-1075. [PubMed: 18948947]

24. Imielinski M, et al. Mapping the hallmarks of lung adenocarcinoma with massively parallel sequencing. Cell. 2012; 150:1107-1120. [PubMed: 22980975]

25. Heist RS, Engelman JA. Snapshot: non-small cell lung cancer. Cancer Cell. 2012; 21:448-448.e2. [PubMed: 22439939]

26. Guagnano V, et al. FGFR genetic alterations predict for sensitivity to NVP-BGJ398, a selective pan-FGFR inhibitor. Cancer Discov. 2012; 2:1118-1133. [PubMed: 23002168]

27. Hammerman PS, et al. Mutations in the $D D R 2$ kinase gene identify a novel therapeutic target in squamous cell lung cancer. Cancer Discov. 2011; 1:78-89. [PubMed: 22328973]

28. Kandoth C, et al. Mutational landscape and significance across 12 major cancer types. Nature. 2013; 502:333-339. [PubMed: 24132290]

29. The Cancer Genome Atlas Research Network (TCGA). Comprehensive molecular profiling of lung adenocarcinoma. Nature. 2014. http://dx.doi.org/10.1038/nature13385

30. Lawrence MS, et al. Discovery and saturation analysis of cancer genes across 21 tumour types. Nature. 2014; 505:495-501. In this study, the genetic complexity of 21 tumour types was directly compared, demonstrating that both lung ADCs and lung SCCs have extremely high somatic mutation rates compared with other tumour types. These authors also present a comprehensive catalogue of cancer genes for each tumour subtype, furthering our global understanding of cancer. [PubMed: 24390350]

31. Govindan R, et al. Genomic landscape of non-small cell lung cancer in smokers and neversmokers. Cell. 2012; 150:1121-1134. [PubMed: 22980976]

32. Barbie DA, et al. Systematic RNA interference reveals that oncogenic $K R A S$-driven cancers require TBK1. Nature. 2009; 462:108-112. [PubMed: 19847166] 
33. Sun N, et al. Isocitrate dehydrogenase 1 is a novel plasma biomarker for the diagnosis of non-small cell lung cancer. Clin Cancer Res. 2013; 19:5136-5145. [PubMed: 24046070]

34. Tan F, et al. Identification of isocitrate dehydrogenase 1 as a potential diagnostic and prognostic biomarker for non-small cell lung cancer by proteomic analysis. Mol Cell Proteomics. 2012; 11008821:M111.

35. Quail DF, Joyce JA. Microenvironmental regulation of tumor progression and metastasis. Nature Med. 2013; 19:1423-1437. [PubMed: 24202395]

36. DuPage M, et al. Endogenous T cell responses to antigens expressed in lung adenocarcinomas delay malignant tumor progression. Cancer Cell. 2011; 19:72-85. By engineering KRAS-driven GEMM tumours to express neoantigens, the authors of this study explored the dynamic responses of endogenous $\mathrm{T}$ cells to naturally arising tumours and informed our ideas about how lung tumours interact with immune cells. [PubMed: 21251614]

37. Murdoch C, Muthana M, Coffelt SB, Lewis CE. The role of myeloid cells in the promotion of tumour angiogenesis. Nature Rev Cancer. 2008; 8:618-631. [PubMed: 18633355]

38. Xiao Z, et al. The pivotal role of IKKa in the development of spontaneous lung squamous cell carcinomas. Cancer Cell. 2013; 23:527-540. [PubMed: 23597566]

39. Vignaud JM, et al. The role of platelet-derived growth factor production by tumor-associated macrophages in tumor stroma formation in lung cancer. Cancer Res. 1994; 54:5455-5463. [PubMed: 7923179]

40. Zaynagetdinov R, et al. A critical role for macrophages in promotion of urethane-induced lung carcinogenesis. J Immunol. 2011; 187:5703-5711. [PubMed: 22048774]

41. Bellocq A, et al. Neutrophil alveolitis in bronchioloalveolar carcinoma: induction by tumor-derived interleukin-8 and relation to clinical outcome. Am J Pathol. 1998; 152:83-92. [PubMed: 9422526]

42. Houghton AM, et al. Neutrophil elastase-mediated degradation of IRS-1 accelerates lung tumor growth. Nature Med. 2010; 16:219-223. [PubMed: 20081861]

43. Mantovani A, Cassatella MA, Costantini C, Jaillon S. Neutrophils in the activation and regulation of innate and adaptive immunity. Nature Rev Immunol. 2011; 11:519-531. [PubMed: 21785456]

44. Brahmer JR, et al. Safety and activity of anti-PD-L1 antibody in patients with advanced cancer. N Engl J Med. 2012; 366:2455-2465. [PubMed: 22658128]

45. Topalian SL, et al. Safety, activity, and immune correlates of anti-PD-1 antibody in cancer. N Engl J Med. 2012; 366:2443-2454. References 44 and 45 were the first studies to show the efficacy and durable response of immunotherapy for the treatment of late-stage NSCLCs. The data suggest a relationship between PDL1 expression on tumour cells and objective response, leading to many new studies examining the expression of this immune-evasion molecule on different NSCLCs. [PubMed: 22658127]

46. Keir ME, Butte MJ, Freeman GJ, Sharpe AH. PD-1 and its ligands in tolerance and immunity. Annu Rev Immunol. 2008; 26:677-704. [PubMed: 18173375]

47. Forde PM, Kelly RJ, Brahmer JR. New strategies in lung cancer: translating immunotherapy into clinical practice. Clin Cancer Res. 2014; 20:1067-1073. [PubMed: 24470514]

48. Akbay EA, et al. Activation of the PD-1 pathway contributes to immune escape in EGFR-driven lung tumors. Cancer Discov. 2013; 3:1355-1363. [PubMed: 24078774]

49. Xu C, et al. Loss of $L k b 1$ and Pten leads to lung squamous cell carcinoma with elevated PD-L1 expression. Cancer Cell. 2014; 25:590-604. [PubMed: 24794706]

50. Ancrile B, Lim KH, Counter CM. Oncogenic Ras-induced secretion of IL6 is required for tumorigenesis. Genes Dev. 2007; 21:1714-1719. [PubMed: 17639077]

51. Gao SP, et al. Mutations in the EGFR kinase domain mediate STAT3 activation via IL-6 production in human lung adenocarcinomas. J Clin Invest. 2007; 117:3846-3856. [PubMed: 18060032]

52. Visvader JE. Cells of origin in cancer. Nature. 2011; 469:314-322. [PubMed: 21248838]

53. Tata PR, et al. Dedifferentiation of committed epithelial cells into stem cells in vivo. Nature. 2013; 503:218-223. [PubMed: 24196716]

54. Chaffer CL, et al. Normal and neoplastic nonstem cells can spontaneously convert to a stem-like state. Proc Natl Acad Sci. 2011; 108:7950-7955. [PubMed: 21498687] 
55. Kwon M, Berns A. Mouse models for lung cancer. Mol Oncol. 2013; 7:165-177. [PubMed: 23481268]

56. Kim C, et al. Identification of bronchioalveolar stem cells in normal lung and lung cancer. Cell. 2005; 121:823-835. This study was the first to characterize a bipotent cell type in the distal lung, termed the BASC. Importantly, the BASCs were shown to expand in response to oncogenic KRAS activation, suggesting that they could function as a cell of origin for lung ADC. [PubMed: 15960971]

57. Tiozzo C, et al. Deletion of Pten expands lung epithelial progenitor pools and confers resistance to airway injury. Am J Respir Crit Care Med. 2009; 180:701-712. [PubMed: 19574443]

58. Ventura JJ, et al. p38a MAP kinase is essential in lung stem and progenitor cell proliferation and differentiation. Nature Genet. 2007; 39:750-758. [PubMed: 17468755]

59. Xu X, et al. Evidence for type II cells as cells of origin of K-Ras-induced distal lung adenocarcinoma. Proc Natl Acad Sci USA. 2012; 109:4910-4915. This study expanded our understanding of cells of origin in GEMMs of lung ADC by using cell-type specific promoters to drive Cre-Lox Kras activation. In contrast to previous theories, the authors find that AT2 cells, rather than BASCs or club cells, are the most likely cells of origin for KRAS-driven tumours. [PubMed: 22411819]

60. Desai TJ, Brownfield DG, Krasnow MA. Alveolar progenitor and stem cells in lung development, renewal and cancer. Nature. 2014; 507:190-194. [PubMed: 24499815]

61. Mainardi S, et al. Identification of cancer initiating cells in $K$-Ras driven lung adenocarcinoma. Proc Natl Acad Sci USA. 2014; 111:255-260. [PubMed: 24367082]

62. Rowbotham SP, Kim CF. Diverse cells at the origin of lung adenocarcinoma. Proc Natl Acad Sci USA. 2014; 111:4745-4746. [PubMed: 24707043]

63. Sutherland KD, et al. Multiple cells-of-origin of mutant K-Ras-induced mouse lung adenocarcinoma. Proc Natl Acad Sci USA. 2014; 111:4952-4957. [PubMed: 24586047]

64. Giangreco A, et al. $\beta$-Catenin determines upper airway progenitor cell fate and preinvasive squamous lung cancer progression by modulating epithelial-mesenchymal transition. J Pathol. 2012; 226:575-587. [PubMed: 22081448]

65. Ji H, et al. LKB1 modulates lung cancer differentiation and metastasis. Nature. 2007; 448:807810. This study validated $L k b 1$ as a bona fide tumour suppressor in NSCLC by deleting $L k b 1$ in the KRAS-driven GEMM of lung cancer. $L k b 1$ loss not only potentiated tumour development but also promoted metastasis and drove tumours with mixed ADC and SCC characteristics. [PubMed: 17676035]

66. Malkoski, SP., et al. Role of PTEN in basal cell derived lung carcinogenesis. Mol Carcinog. 2013. http://dx.doi.org/10.1002/mc.22030

67. Beck B, Blanpain C. Unravelling cancer stem cell potential. Nature Rev Cancer. 2013; 13:727-738. [PubMed: 24060864]

68. Li F, Tiede B, Massague J, Kang Y. Beyond tumorigenesis: cancer stem cells in metastasis. Cell Res. 2007; 17:3-14. [PubMed: 17179981]

69. Jiang F, et al. Aldehyde dehydrogenase 1 is a tumor stem cell-associated marker in lung cancer. Mol Cancer Res. 2009; 7:330-338. [PubMed: 19276181]

70. Lau AN, et al. Tumor-propagating cells and Yap/Taz activity contribute to lung tumor progression and metastasis. EMBO J. 2014; 33:468-481. [PubMed: 24497554]

71. Liu J, et al. Lung cancer tumorigenicity and drug resistance are maintained through $\mathrm{ALDH}^{\text {hi }}{ }^{\mathrm{CD}} 44^{\text {hi }}$ tumor initiating cells. Oncotarget. 2013; 4:1698-1711. [PubMed: 24091605]

72. Sullivan JP, et al. Aldehyde dehydrogenase activity selects for lung adenocarcinoma stem cells dependent on Notch signaling. Cancer Res. 2010; 70:9937-9948. [PubMed: 21118965]

73. Zheng Y, et al. A rare population of $\mathrm{CD} 24^{+} \mathrm{ITGB}^{+}{ }^{+} \mathrm{Notch}^{\text {hi }}$ cells drives tumor propagation in NSCLC and requires Notch3 for self-renewal. Cancer Cell. 2013; 24:59-74. [PubMed: 23845442]

74. Curtis SJ, et al. Primary tumor genotype is an important determinant in identification of lung cancer propagating cells. Cell Stem Cell. 2010; 7:127-133. In this study, an orthotopic serial transplantation model of primary murine lung tumour cells was used to identify the first bona fide TPC population in lung cancer. Importantly, TPC phenotype was shown to be dependent on 
primary tumour genotype, suggesting that TPC characteristics will differ for different driver mutations. [PubMed: 20621056]

75. Sequist LV, et al. Genotypic and histological evolution of lung cancers acquiring resistance to EGFR inhibitors. Sci Transl Med. 2011; 3:75ra26.

76. Song $\mathrm{H}$, et al. Functional characterization of pulmonary neuroendocrine cells in lung development, injury, and tumorigenesis. Proc Natl Acad Sci USA. 2012; 109:17531-17536. [PubMed: 23047698]

77. Park KS, et al. Characterization of the cell of origin for small cell lung cancer. Cell Cycle. 2011; 10:2806-2815. [PubMed: 21822053]

78. Sutherland KD, et al. Cell of origin of small cell lung cancer: inactivation of Trp53 and $R b 1$ in distinct cell types of adult mouse lung. Cancer Cell. 2011; 19:754-764. [PubMed: 21665149]

79. Gazdar AF, Girard L, Lockwood WW, Lam WL, Minna JD. Lung cancer cell lines as tools for biomedical discovery and research. J Natl Cancer Inst. 2010; 102:1310-1321. [PubMed: 20679594]

80. Dow LE, Lowe SW. Life in the fast lane: mammalian disease models in the genomics era. Cell. 2012; 148:1099-1109. [PubMed: 22424222]

81. Levy MA, Lovly CM, Pao W. Translating genomic information into clinical medicine: lung cancer as a paradigm. Genome Res. 2012; 22:2101-2108. [PubMed: 23019146]

82. Shaw AT, Hsu PP, Awad MM, Engelman JA. Tyrosine kinase gene rearrangements in epithelial malignancies. Nature Rev Cancer. 2013; 13:772-787. [PubMed: 24132104]

83. Camidge DR, et al. Activity and safety of crizotinib in patients with ALK-positive non-small-cell lung cancer: updated results from a phase 1 study. Lancet Oncol. 2012; 13:1011-1019. [PubMed: 22954507]

84. Mok TS, et al. Gefitinib or carboplatin-paclitaxel in pulmonary adenocarcinoma. N Engl J Med. 2009; 361:947-957. [PubMed: 19692680]

85. Shaw AT, et al. Effect of crizotinib on overall survival in patients with advanced non-small-cell lung cancer harbouring $A L K$ gene rearrangement: a retrospective analysis. Lancet Oncol. 2011; 12:1004-1012. [PubMed: 21933749]

86. Sequist LV, et al. Phase I study of BGJ398, a selective pan-FGFR inhibitor in genetically preselected advanced solid tumors. AACR Meet. 2014:CT326. Abstr.

87. Katayama R, et al. Mechanisms of acquired crizotinib resistance in ALK-rearranged lung cancers. Sci Transl Med. 2012; 4:120ra17.

88. Kobayashi S, et al. EGFR mutation and resistance of non-small-cell lung cancer to gefitinib. $\mathrm{N}$ Engl J Med. 2005; 352:786-792. [PubMed: 15728811]

89. Shaw AT, et al. Ceritinib in $A L K$-rearranged non-small-cell lung cancer. N Engl J Med. 2014; 370:1189-1197. [PubMed: 24670165]

90. Walter AO, et al. Discovery of a mutant-selective covalent inhibitor of EGFR that overcomes T790M-mediated resistance in NSCLC. Cancer Discov. 2013; 3:1404-1415. [PubMed: 24065731]

91. Cross, DA., et al. AZD9291, an irreversible EGFR TKI, overcomes T790M-mediated resistance to EGFR inhibitors in lung cancer. Cancer Discov. 2014. http://dx.doi.org/ 10.1158/2159-8290.CD-14-0337

92. Yonesaka K, et al. Activation of ERBB2 signaling causes resistance to the EGFR-directed therapeutic antibody cetuximab. Sci Transl Med. 2011; 3:99ra86.

93. Zhang Z, et al. Activation of the AXL kinase causes resistance to EGFR-targeted therapy in lung cancer. Nature Genet. 2012; 44:852-860. [PubMed: 22751098]

94. Ercan D, et al. Reactivation of ERK signaling causes resistance to EGFR kinase inhibitors. Cancer Discov. 2012; 2:934-947. [PubMed: 22961667]

95. Lin L, Bivona TG. Mechanisms of resistance to epidermal growth factor receptor inhibitors and novel therapeutic strategies to overcome resistance in NSCLC patients. Chemother Res Pract. 2012; 2012:817297. [PubMed: 22970367]

96. Bivona TG, et al. FAS and NF- $\kappa$ B signalling modulate dependence of lung cancers on mutant EGFR. Nature. 2011; 471:523-526. [PubMed: 21430781] 
97. Xu K, et al. EZH2 Oncogenic Activity in Castration-Resistant Prostate Cancer Cells Is PolycombIndependent. Science. 2012; 338:1465-1469. [PubMed: 23239736]

98. Chen Z, et al. A murine lung cancer co-clinical trial identifies genetic modifiers of therapeutic response. Nature. 2012; 483:613-617. This study was the first of its kind to use GEMMs to conduct a co-clinical trial that mirrored an ongoing human clinical trial in patients with $K R A S$ mutant lung cancer. The study found genetic predictors of therapy response and provided a model for future co-clinical trials aimed at accelerating the pace of novel therapeutic development. [PubMed: 22425996]

99. Engelman JA, et al. Effective use of PI3K and MEK inhibitors to treat mutant Kras G12D and PIK3CA H1047R murine lung cancers. Nature Med. 2008; 14:1351-1356. [PubMed: 19029981]

100. Janne PA, et al. Selumetinib plus docetaxel for KRAS-mutant advanced non-small-cell lung cancer: a randomised, multicentre, placebo-controlled, phase 2 study. Lancet Oncol. 2013; 14:38-47. [PubMed: 23200175]

101. Lim SM, et al. Therapeutic targeting of oncogenic K-Ras by a covalent catalytic site inhibitor. Angew Chem Int Ed Engl. 2014; 53:199-204. [PubMed: 24259466]

102. Ostrem JM, Peters U, Sos ML, Wells JA, Shokat KM. K-Ras ${ }^{\text {12C }}$ inhibitors allosterically control GTP affinity and effector interactions. Nature. 2013; 503:548-551. [PubMed: 24256730]

103. Bass AJ, et al. SOX2 is an amplified lineage-survival oncogene in lung and esophageal squamous cell carcinomas. Nature Genet. 2009; 41:1238-1242. [PubMed: 19801978]

104. Iwakawa R, et al. MYC amplification as a prognostic marker of early-stage lung adenocarcinoma identified by whole genome copy number analysis. Clin Cancer Res. 2011; 17:1481-1489. [PubMed: 21148746]

105. Lin CY, et al. Transcriptional amplification in tumor cells with elevated c-Myc. Cell. 2012; 151:56-67. [PubMed: 23021215]

106. Engelman JA, Janne PA. Mechanisms of acquired resistance to epidermal growth factor receptor tyrosine kinase inhibitors in non-small cell lung cancer. Clin Cancer Res. 2008; 14:2895-2899. [PubMed: 18483355]

107. Grosso JF, Jure-Kunkel MN. CTLA-4 blockade in tumor models: an overview of preclinical and translational research. Cancer Immun. 2013; 13:5. [PubMed: 23390376]

108. Lee DW, Barrett DM, Mackall C, Orentas R, Grupp SA. The future is now: chimeric antigen receptors as new targeted therapies for childhood cancer. Clin Cancer Res. 2012; 18:2780-2790. [PubMed: 22589486]

109. Tseng D, et al. Anti-CD47 antibody-mediated phagocytosis of cancer by macrophages primes an effective antitumor T-cell response. Proc Natl Acad Sci USA. 2013; 110:11103-11108. [PubMed: 23690610]

110. Zhang B. CD73: a novel target for cancer immunotherapy. Cancer Res. 2010; 70:6407-6411. [PubMed: 20682793]

111. Sandler A, et al. Paclitaxel-carboplatin alone or with bevacizumab for non-small-cell lung cancer. N Engl J Med. 2006; 355:2542-2550. [PubMed: 17167137]

112. Schoenfeld J, et al. Active immunotherapy induces antibody responses that target tumor angiogenesis. Cancer Res. 2010; 70:10150-10160. [PubMed: 21159637]

113. Yuan J, et al. Pretreatment serum VEGF is associated with clinical response and overall survival in advanced melanoma patients treated with ipilimumab. Cancer Immunol Res. 2014; 2:127-132. [PubMed: 24778276]

114. Lee JH, et al. Lung stem cell differentiation in mice directed by endothelial cells via a BMP4NFATc1-thrombospondin-1 axis. Cell. 2014; 156:440-455. [PubMed: 24485453]

115. Straussman R, et al. Tumour micro-environment elicits innate resistance to RAF inhibitors through HGF secretion. Nature. 2012; 487:500-504. [PubMed: 22763439]

116. Filippakopoulos P, et al. Selective inhibition of BET bromodomains. Nature. 2010; 468:10671073. [PubMed: 20871596]

117. Shimamura T, et al. Efficacy of BET bromodomain inhibition in Kras-mutant non-small cell lung cancer. Clin Cancer Res. 2013; 19:6183-6192. [PubMed: 24045185]

118. Liu Y, et al. Metabolic and functional genomic studies identify deoxythymidylate kinase as a target in LKB1-mutant lung cancer. Cancer Discov. 2013; 3:870-879. [PubMed: 23715154] 
119. Molina-Arcas M, Hancock DC, Sheridan C, Kumar MS, Downward J. Coordinate direct input of both KRAS and IGF1 receptor to activation of PI3 kinase in KRAS-mutant lung cancer. Cancer Discov. 2013; 3:548-563. [PubMed: 23454899]

120. Orita $\mathrm{H}$, et al. Selective inhibition of fatty acid synthase for lung cancer treatment. Clin Cancer Res. 2007; 13:7139-7145. [PubMed: 18056164]

121. Shackelford DB, et al. LKB1 inactivation dictates therapeutic response of non-small cell lung cancer to the metabolism drug phenformin. Cancer Cell. 2013; 23:143-158. [PubMed: 23352126]

122. Hughes LA, et al. The CpG island methylator phenotype: what's in a name? Cancer Res. 2013; 73:5858-5868. [PubMed: 23801749]

123. Losman JA, Kaelin WG Jr. What a difference a hydroxyl makes: mutant IDH, (R)-2hydroxyglutarate, and cancer. Genes Dev. 2013; 27:836-852. [PubMed: 23630074]

124. Shinjo K, et al. Integrated analysis of genetic and epigenetic alterations reveals $\mathrm{CpG}$ island methylator phenotype associated with distinct clinical characters of lung adenocarcinoma. Carcinogenesis. 2012; 33:1277-1285. [PubMed: 22532250]

125. Chen Z, et al. Inhibition of ALK, PI3K/MEK, and HSP90 in murine lung adenocarcinoma induced by $E M L 4-A L K$ fusion oncogene. Cancer Res. 2010; 70:9827-9836. [PubMed: 20952506]

126. Ji H, et al. The impact of human EGFR kinase domain mutations on lung tumorigenesis and in vivo sensitivity to EGFR-targeted therapies. Cancer Cell. 2006; 9:485-495. [PubMed: 16730237]

127. Chen Z, et al. Co-clinical trials demonstrate superiority of crizotinib to chemotherapy in ALKrearranged non-small cell lung cancer and predict strategies to overcome resistance. Clin Cancer Res. 2014; 20:1204-1211. [PubMed: 24327273]

128. Jackson EL, et al. The Differential effects of mutant p53 alleles on advanced murine lung cancer. Cancer Res. 2005; 65:10280-10288. [PubMed: 16288016]

129. Oliver TG, et al. Chronic cisplatin treatment promotes enhanced damage repair and tumor progression in a mouse model of lung cancer. Genes Dev. 2010; 24:837-852. [PubMed: 20395368]

130. Blasco RB, et al. c-Raf, but not B-Raf, is essential for development of $K$-Ras oncogene-driven non-small cell lung carcinoma. Cancer Cell. 2011; 19:652-663. [PubMed: 21514245]

131. Puyol M, et al. A synthetic lethal interaction between K-Ras oncogenes and Cdk4 unveils a therapeutic strategy for non-small cell lung carcinoma. Cancer Cell. 2010; 18:63-73. [PubMed: 20609353]

132. Savino M, et al. The action mechanism of the Myc inhibitor termed Omomyc may give clues on how to target Myc for cancer therapy. PLoS ONE. 2011; 6:e22284. [PubMed: 21811581]

133. Soucek L, et al. Modelling Myc inhibition as a cancer therapy. Nature. 2008; 455:679-683. [PubMed: 18716624]

134. Soucek L, et al. Inhibition of Myc family proteins eradicates KRas-driven lung cancer in mice. Genes Dev. 2013; 27:504-513. [PubMed: 23475959]

135. Zhang WC, et al. Glycine decarboxylase activity drives non-small cell lung cancer tumorinitiating cells and tumorigenesis. Cell. 2012; 148:259-272. [PubMed: 22225612]

136. Rock JR, et al. Basal cells as stem cells of the mouse trachea and human airway epithelium. Proc Natl Acad Sci USA. 2009; 106:12771-12775. In this study, the KRT5 ${ }^{+}$and p63 $^{+}$basal cells of the trachea were shown to be true stem or progenitor cells through lineage tracing experiments during development and tracheal epithelial repair. The authors isolated similar cells from human tracheas and showed that both murine and human cells can be cultured as tracheospheres in threedimensional Matrigel-containing transwells. [PubMed: 19625615]

137. Hegab AE, et al. Novel stem/progenitor cell population from murine tracheal submucosal gland ducts with multipotent regenerative potential. Stem Cells. 2011; 29:1283-1293. [PubMed: 21710468]

138. Rock JR, Hogan BLM. Epithelial progenitor cells in lung development, maintenance, repair, and disease. Annu Rev Cell Dev Biol. 2011; 27:493-512. [PubMed: 21639799]

139. Rawlins EL, et al. The role of Scgb1a ${ }^{+}$Clara cells in the long-term maintenance and repair of lung airway, but not alveolar, epithelium. Cell Stem Cell. 2009; 4:525-534. [PubMed: 19497281] 
140. Teixeira VH, et al. Stochastic homeostasis in human airway epithelium is achieved by neutral competition of basal cell progenitors. eLife. 2013; 2 http://dx.doi.org/10.7554/eLife. 00966\#sthash.XxrCqaIk.dpuf.

141. Teisanu RM, Lagasse E, Whitesides JF, Stripp BR. Prospective Isolation of Bronchiolar Stem Cells Based Upon Immunophenotypic and Autofluorescence Characteristics. Stem Cells. 2009; 27:612-622. [PubMed: 19056905]

142. Barkauskas CE, et al. Type 2 alveolar cells are stem cells in adult lung. J Clin Invest. 2013; 123:3025-3036. This study was the first to show that AT2 cells can function as facultative stem or progenitor cells in the adult lung to differentiate into both AT2 and AT1 lineages after injury. [PubMed: 23921127]

143. Chapman HA, et al. Integrin a6 64 identifies an adult distal lung epithelial population with regenerative potential in mice. J Clin Invest. 2011; 121:2855-2862. [PubMed: 21701069]

144. Tropea KA, et al. Bronchioalveolar stem cells increase after mesenchymal stromal cell treatment in a mouse model of bronchopulmonary dysplasia. Am J Physiol Lung Cell Mol Physiol. 2012; 302:L829-L837. [PubMed: 22328358]

145. Zacharek SJ, et al. Lung stem cell self-renewal relies on BMI1-dependent control of expression at imprinted loci. Cell Stem Cell. 2010; 9:272-281.

146. Rock JR, et al. Multiple stromal populations contribute to pulmonary fibrosis without evidence for epithelial to mesenchymal transition. Proc Natl Acad Sci USA. 2011; 108:E1475-E1483. [PubMed: 22123957]

147. McQualter JL, Yuen K, Williams B, Bertoncello I. Evidence of an epithelial stem/progenitor cell hierarchy in the adult mouse lung. Proc Natl Acad Sci USA. 2010; 107:1414-1419. [PubMed: 20080639]

148. Hegab AE, et al. Isolation and in vitro characterization of basal and submucosal gland duct stem/ progenitor cells from human proximal airways. Stem Cells Translat Med. 2012; 1:719-724.

149. Kajstura J, et al. Evidence for human lung stem cells. New Engl J Med. 2011; 364:1795-1806. [PubMed: 21561345]

150. Marek L, et al. Fibroblast growth factor (FGF) and FGF receptor-mediated autocrine signaling in non-small-cell lung cancer cells. Mol Pharmacol. 2009; 75:196-207. [PubMed: 18849352]

151. Liao RG, et al. Inhibitor-sensitive FGFR2 and FGFR3 mutations in lung squamous cell carcinoma. Cancer Res. 2013; 73:5195-5205. [PubMed: 23786770]

152. Xu L, et al. Combined EGFR/MET or EGFR/HSP90 inhibition is effective in the treatment of lung cancers codriven by mutant EGFR containing T790M and MET. Cancer Res. 2012; 72:3302-3311. [PubMed: 22552292]

153. Davies KD, et al. Identifying and targeting ROS1 gene fusions in non-small cell lung cancer. Clin Cancer Res. 2012; 18:4570-4579. [PubMed: 22919003]

154. Takeuchi K, et al. RET, ROS1 and ALK fusions in lung cancer. Nature Med. 2012; 18:378-381. [PubMed: 22327623]

155. Wang SE, et al. HER2 kinase domain mutation results in constitutive phosphorylation and activation of HER2 and EGFR and resistance to EGFR tyrosine kinase inhibitors. Cancer Cell. 2006; 10:25-38. [PubMed: 16843263]

156. McDermott U, et al. Ligand-dependent platelet-derived growth factor receptor (PDGFR)-a activation sensitizes rare lung cancer and sarcoma cells to PDGFR kinase inhibitors. Cancer Res. 2009; 69:3937-3946. [PubMed: 19366796]

157. Jackson EL, et al. Analysis of lung tumor initiation and progression using conditional expression of oncogenic $K$-ras. Genes Dev. 2001; 15:3243-3248. GEMMs of lung cancer have been developed largely based on this prototypical study, in which the Cre-Lox system was used to induce oncogenic Kras expression specifically in the lung through Adeno-Cre intranasal instillation. [PubMed: 11751630]

158. Mascaux $\mathrm{C}$, et al. The role of RAS oncogene in survival of patients with lung cancer: a systematic review of the literature with meta-analysis. Br J Cancer. 2005; 92:131-139. [PubMed: 15597105]

159. De Raedt T, et al. Exploiting cancer cell vulnerabilities to develop a combination therapy for rasdriven tumors. Cancer Cell. 2011; 20:400-413. [PubMed: 21907929] 
160. Paik PK, et al. Clinical characteristics of patients with lung adenocarcinomas harboring $B R A F$ mutations. J Clin Oncol. 2011; 29:2046-2051. [PubMed: 21483012]

161. Kawano O, et al. PIK3CA mutation status in Japanese lung cancer patients. Lung Cancer. 2006; 54:209-215. [PubMed: 16930767]

162. Marks JL, et al. Novel MEK1 mutation identified by mutational analysis of epidermal growth factor receptor signaling pathway genes in lung adenocarcinoma. Cancer Res. 2008; 68:55245528. [PubMed: 18632602]

163. Licciulli S, et al. Notch1 is required for Kras-induced lung adenocarcinoma and controls tumor cell survival via p53. Cancer Res. 2013; 73:5974-5984. [PubMed: 23943799]

164. Westhoff B, et al. Alterations of the Notch pathway in lung cancer. Proc Natl Acad Sci USA. 2009; 106:22293-22298. [PubMed: 20007775]

165. Issaeva I, et al. Knockdown of ALR (MLL2) reveals ALR target genes and leads to alterations in cell adhesion and growth. Mol Cell Biol. 2007; 27:1889-1903. [PubMed: 17178841]

166. Takawa M, et al. Validation of the histone methyltransferase EZH2 as a therapeutic target for various types of human cancer and as a prognostic marker. Cancer Sci. 2011; 102:1298-1305. [PubMed: 21539681]

167. Yang H, et al. Tumor development is associated with decrease of TET gene expression and 5methylcytosine hydroxylation. Oncogene. 2013; 32:663-669. [PubMed: 22391558]

168. Gao Q, et al. Deletion of the de novo DNA methyltransferase Dnmt3a promotes lung tumor progression. Proc Natl Acad Sci USA. 2011; 108:18061-18066. [PubMed: 22011581]

169. Ohta T, et al. Loss of Keap1 function activates Nrf2 and provides advantages for lung cancer cell growth. Cancer Res. 2008; 68:1303-1309. [PubMed: 18316592]

170. Singh A, et al. Dysfunctional KEAP1-NRF2 interaction in non-small-cell lung cancer. PLoS Med. 2006; 3:e420. [PubMed: 17020408]

171. Wang Y, Zhang Z, Kastens E, Lubet RA, You M. Mice with alterations in both p53 and Ink4a/Arf display a striking increase in lung tumor multiplicity and progression: differential chemopreventive effect of budesonide in wild-type and mutant A/J mice. Cancer Res. 2003; 63:4389-4395. [PubMed: 12907609]

172. Lou-Qian Z, et al. The prognostic value of epigenetic silencing of $p 16$ gene in NSCLC patients: a systematic review and meta-analysis. PLoS ONE. 2013; 8:e54970. [PubMed: 23372805]

173. Mitsudomi T, Hamajima N, Ogawa M, Takahashi T. Prognostic significance of p53 alterations in patients with non-small cell lung cancer: a meta-analysis. Clin Cancer Res. 2000; 6:4055-4063. [PubMed: 11051256]

174. Sanchez-Cespedes M, et al. Inactivation of $L K B 1 / S T K 11$ is a common event in adenocarcinomas of the lung. Cancer Res. 2002; 62:3659-3662. [PubMed: 12097271]

175. Iwanaga $\mathrm{K}$, et al. Pten inactivation accelerates oncogenic $K$-ras-initiated tumorigenesis in a mouse model of lung cancer. Cancer Res. 2008; 68:1119-1127. [PubMed: 18281487]

176. Soria JC, et al. Lack of PTEN expression in non-small cell lung cancer could be related to promoter methylation. Clin Cancer Res. 2002; 8:1178-1184. [PubMed: 12006535] 


\section{Box 1}

\section{Mouse models}

Genetically engineered mouse models (GEMMs) have enabled numerous studies of nonsmall-cell lung cancer (NSCLC) that would not be possible using patient samples or cancer cell lines: for example, preclinical or co-clinical trials of targeted therapies, the study of metastatic and transplanted disease and examination of tumour cells of origin $^{25,49,74,98,125,126}$. Today, GEMMs for most of the common NSCLC driver mutations have been generated, including for $K R A S$, epidermal growth factor receptor $(E G F R)$, and echinoderm microtubule-associated protein-like 4 (EML4)-anaplastic lymphoma kinase $(A L K)$; and despite their lack of genetic complexity compared to human cancers, they have shown some remarkable similarities in pathological features and treatment responses to the human disease $\mathrm{e}^{98,125-127}$.

GEMMs are particularly informative when the net effects of several mutations need to be determined in vivo. For example, the conditional oncogenic Kras ${ }^{G 12 D}$ mouse model has been used to elucidate the steps from early to late tumorigenesis, owing to the temporal control it affords ${ }^{128}$, and it is easy to combine with mice bearing conditional null alleles for other genes of interest. For example, Kras ${ }^{G 12 D}$ tumours only reach a full adenocarcinoma stage with a very long latency, but $K r a s^{G 12 D}$-expressing and Trp53-null tumours are more advanced and show a decreased response to certain treatment strategies when compared to $\mathrm{Kras}^{G 12 D}$ tumours ${ }^{128,129}$. Simultaneous inactivation of Pten and liver kinase B1 $(L k b I)$ in the lung produced only squamous cell carcinoma (SCC $)^{49}$, and this fits with the preclinical observations that PI3K and mTOR pathways are activated in most human lung SCC tumours ${ }^{20,49,65}$. Similar genetic breeding schemes can be used to identify and validate potential treatment targets through in vivo synthetic lethal experiments. Elegant studies have recently shown that MYC, cyclin-dependent kinase 4 (CDK4) and CRAF are crucial KRAS effectors that can lead to synthetic lethality when genetically inactivated in tumours with activated KRAS ${ }^{130-134}$.

The assessment of immunotherapeutics and the dynamic interactions between tumour cells and their microenvironment using GEMMs (which are immunocompetent) is another emerging research direction. Experiments of particular interest include gene expression and pathway activation profiles for each cell type within the tumour; genotype- or treatment-dependent influences on the tumour microenvironment; and effects of individual or combination therapies on tumour cells, immune cells and other cell types within the tumour microenvironment.

Patient-derived xenograft (PDX) models provide an alternative and complementary method to GEMMs to address human-murine differences and allow for expansion of patient material to perform assays such as metabolomic and serial transplantation ${ }^{135}$. A 'humanized' lung and even a 'humanized' immune system in the mouse might offer a more accurate means to model NSCLC. 


\section{Box 2}

\section{Lung stem and progenitor cell populations}

Genetic lineage tracing and cell biology approaches have shown that the murine lung contains region-specific stem and progenitor cell populations that respond to local injury. Basal cells function as stem cells for the trachea, main bronchi and upper airways, where they can replace the pseudostratified epithelium, including secretory club cells (previously known as Clara cells), mucus-producing goblet cells and ciliated cells ${ }^{136-138}$. In more distal airways, club cells are a self-renewing population that maintains the ciliated cells ${ }^{139}$, and subsets of club cells, such as bronchiolar progenitors, can give rise to ciliated and club cell lineages after injury ${ }^{140,141}$. In the alveolar space, where gas exchange is carried out by alveolar epithelial type 1 (AT1) cells, the surfactant-expressing AT2 cells can function as stem cells ${ }^{60,142}$. Another alveolar cell population, expressing a6 $\beta 4$ integrin, can also produce alveolar epithelia ${ }^{142,143}$. Bronchioalveolar stem cells (BASCs), which reside between the airway and alveolar space, can give rise to both epithelial lineages ${ }^{56,114,144-146}$. Murine proximal and distal lung stem cells can be isolated by fluorescence-activated cell sorting that uses different cell surface markers and can be grown in three-dimensional culture systems to study their differentiation potential ${ }^{114,136,141,147}$. Basal cells can be isolated from mouse or human lung on the basis of their expression of nerve growth factor receptor (NGFR) ${ }^{136,148}$, and AT2 cells can be purified from distal lung - most recently with the marker HTII-280 (REF. ${ }^{142}$ ). Several other human lung stem cell populations have been reported in the human lung, but their roles have been controversial ${ }^{149}$, and this points to the characterization of human lung stem and progenitor cells as an important area for future research. Furthermore, precisely how these cell types change their lineage potential in the face of oncogenic insult coupled with injury is unknown and is likely to influence tumorigenesis; injury and transformation might substantially alter plasticity ${ }^{53}$. A better understanding of lung stem and progenitor cells and methods for their analysis would open up new ways to explore the cellular origins of lung tumorigenesis. 


\section{Box 3}

\section{Patient stratification}

Stratification and treatment selection for patients with non-small-cell lung cancer (NSCLC) heavily relies on radiographical and pathological evaluation in standard clinical practice. In recent years, molecular diagnostic platforms have been gradually introduced into this process. Today, many cancer centres and hospitals have adopted some degree of genetic diagnosis. Commonly accepted oncogenic driver mutations, including $K R A S$, epidermal growth factor receptor $(E G F R)$, anaplastic lymphoma kinase $(A L K), R O S$ and $B R A F$, are being sequenced and detected as a standard diagnosis procedure. Increasingly, mutation-based decision-making procedures are being integrated in the clinic, and we expect that additional novel technology platforms that stratify tumours according to the specific metabolome, epigenome and immune profile of each patient will be applied in the clinic in the near future. The anticipated challenge is how best to verify and use the vast amounts of sequencing information for translation to the clinic. Ongoing efforts seek to optimize data mining that will link existing genomic and biological data with clinical databases. In 2013, the Broad Institute, Cambridge, Massachusetts, USA, launched a global alliance that intends to share genomic and clinical data. A similar effort at Vanderbilt University, Nashville, Tennessee, USA, which is mediated by a publicly accessible website (My Cancer Genome), emphasizes the clinical application of cancer research. Worldwide efforts, such as the International Cancer Genome Consortium (ICGC) and the Catalogue of Somatic Mutations in Cancer (COSMIC) from the Sanger Institute, Hinxton, UK, and joint efforts in European countries to establish organoid cultures from primary tumours or biopsies from patients are also under way. Despite these independent efforts to integrate data sets, a more organized programme is needed on the national and international levels. The US National Center for Biotechnology Information recently initiated whole-genome sequencing to identify rare, druggable oncogenic events in patients who showed isolated but marked responses to certain drugs; this may represent the first exploratory step towards an integrated programme. 


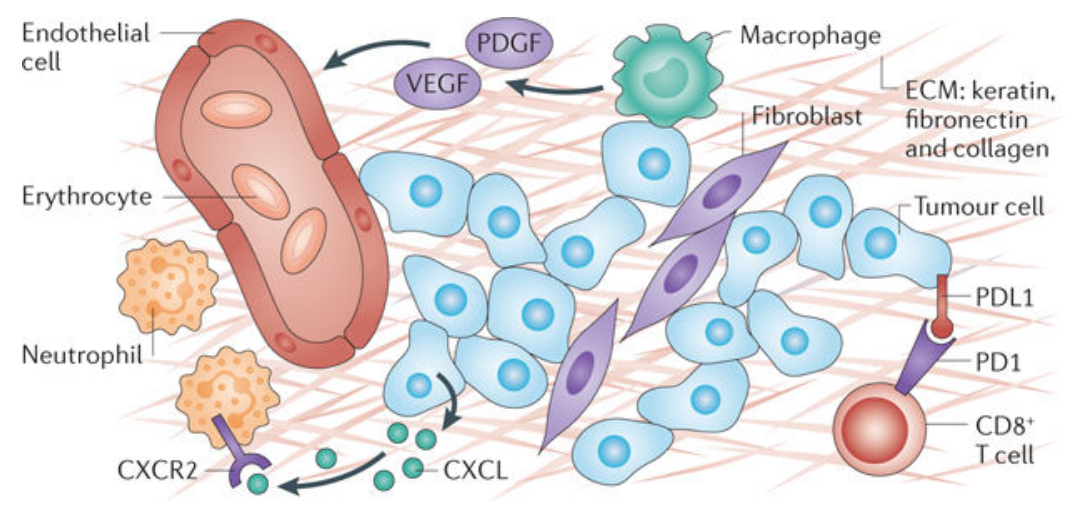

Figure 1. The lung cancer microenvironment

The tumour microenvironment, including endothelial cells, fibroblasts and myeloid cells, among others, has important roles in determining the characteristics of lung tumours. It is likely that a combination of the cell of origin, genetic alterations and microenvironmental factors all contribute to the lineage identity of lung tumours. Extracellular matrix (ECM), which often consists of keratins in lung squamous cell carcinoma and fibronectin in desmoplastic lung adenocarcinomas, gives structural support to tumour cells and is associated with tumour-associated fibroblasts. Blood vessels are newly formed at the tumour site by recruitment of endothelial cells via platelet-derived growth factor (PDGF) and vascular endothelial growth factor (VEGF), among others. As the blood and lymphatic vessels form, numerous blood cells, including macrophages, neutrophils, T cells and B cells, home to the tumours. In particular, tumours can recruit neutrophils through secretion of CXC-chemokine ligand (CXCL) family members, which bind to the neutrophil receptor CXCR2. In addition, tumour cells often express immune checkpoint molecules, such as programmed cell death 1 ligand 1 (PDL1), to attenuate a cytotoxic response from T cells. PD1, programmed cell death 1. 


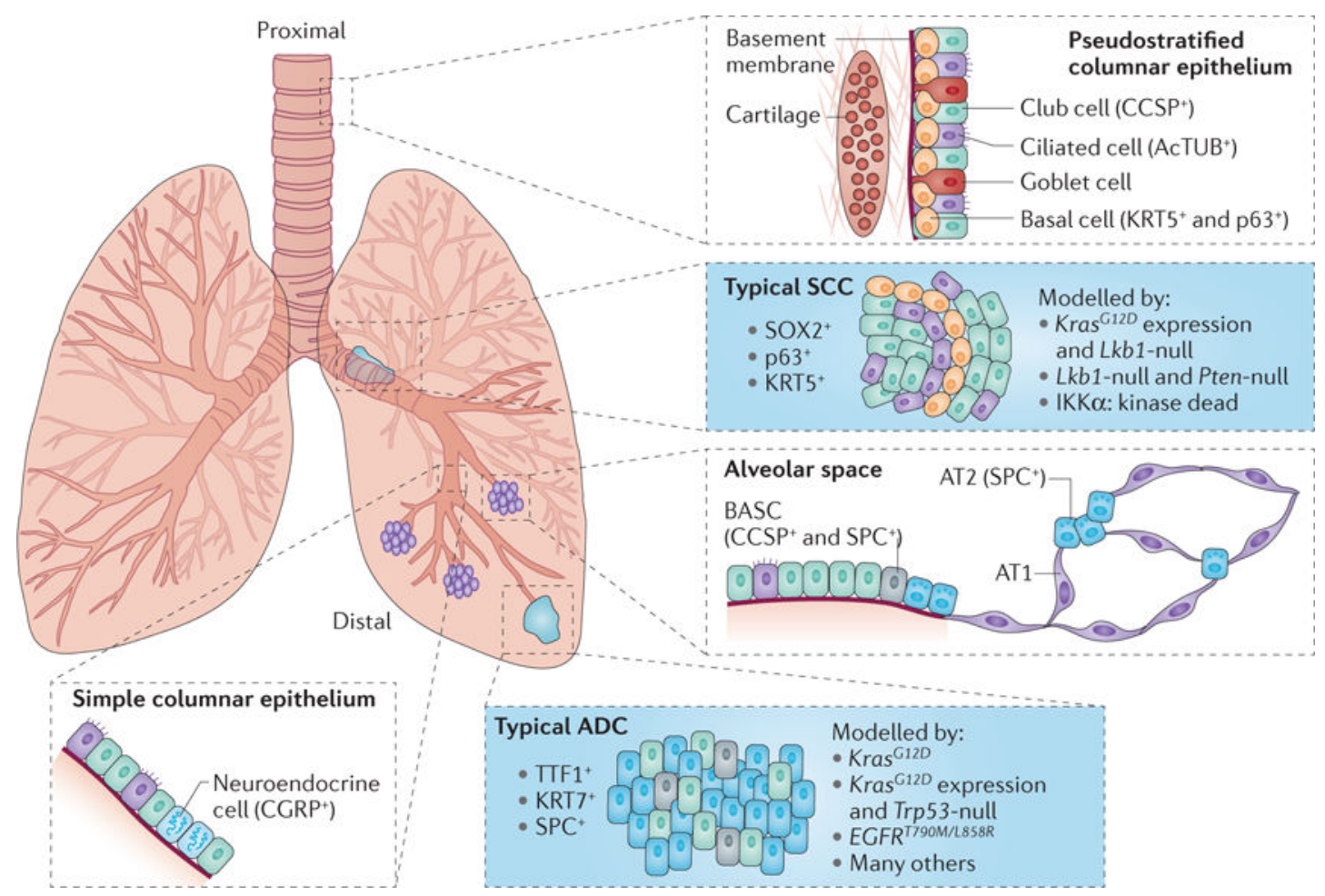

Figure 2. A diagram of proximal and distal lung cells, indicating markers that are retained in carcinomas and putative squamous cell carcinoma (SCC) and adenocarcinoma (ADC) cells of origin

Diverse lung stem or progenitor cell populations are thought to have the ability to drive lung oncogenesis in different contexts. In the proximal lung, the tracheal basal cell has been proposed to be the cell of origin for lung SCC. The evidence for this relationship includes the expression of p63, SRY-box 2 (SOX2) and keratin 5 (KRT5) within the basal cells, squamous metaplasia of the basal cells (common in smokers), and squamous cell carcinomas. Squamous tumours are modelled in mice by $\mathrm{Kras}^{G 12 D}$ expression and liver kinase B1 ( $L k b 1)$ knockout (20\% of lesions are squamous), knocking in a germline dominant-negative kinase-dead inhibitor of nuclear factor- $\kappa \mathrm{B}$ kinase subunit- $a$ (IKKa) and knocking out both Lkb1 and Pten (100\% of lesions are squamous for the second two models). Two bronchiolar cell populations, the bronchiolar progenitor cells and the bronchioalveolar stem cells (BASCs) may also be able to give rise to tumours with squamous characteristics, although experimental lineage tracing is needed to confirm this theory. ADCs can be modelled by $\operatorname{Kras}^{G 12 D}$ expression (long latency), Kras ${ }^{G 12 D}$ expression and Trp53-null, and epidermal growth factor receptor $(E G F R)^{T 790 M / L 858 R}$, among other genetic models, and they are thought to arise from more proximal airway cells. These tumours often retain characteristics of proximal airways, such as the expression of surfactant protein C (SPC), KRT7 and thyroid transcription factor 1 (TTF1). Again, BASCs or bronchiolar progenitor cells, which are able to give rise to alveolar lineages after lung injury, may likewise be able to give rise to tumours with alveolar characteristics. AcTUB, acetylated tubulin; AT, alveolar epithelial type; CCSP, club cell secretory protein; CGRP, calcitonin gene-related peptide. 


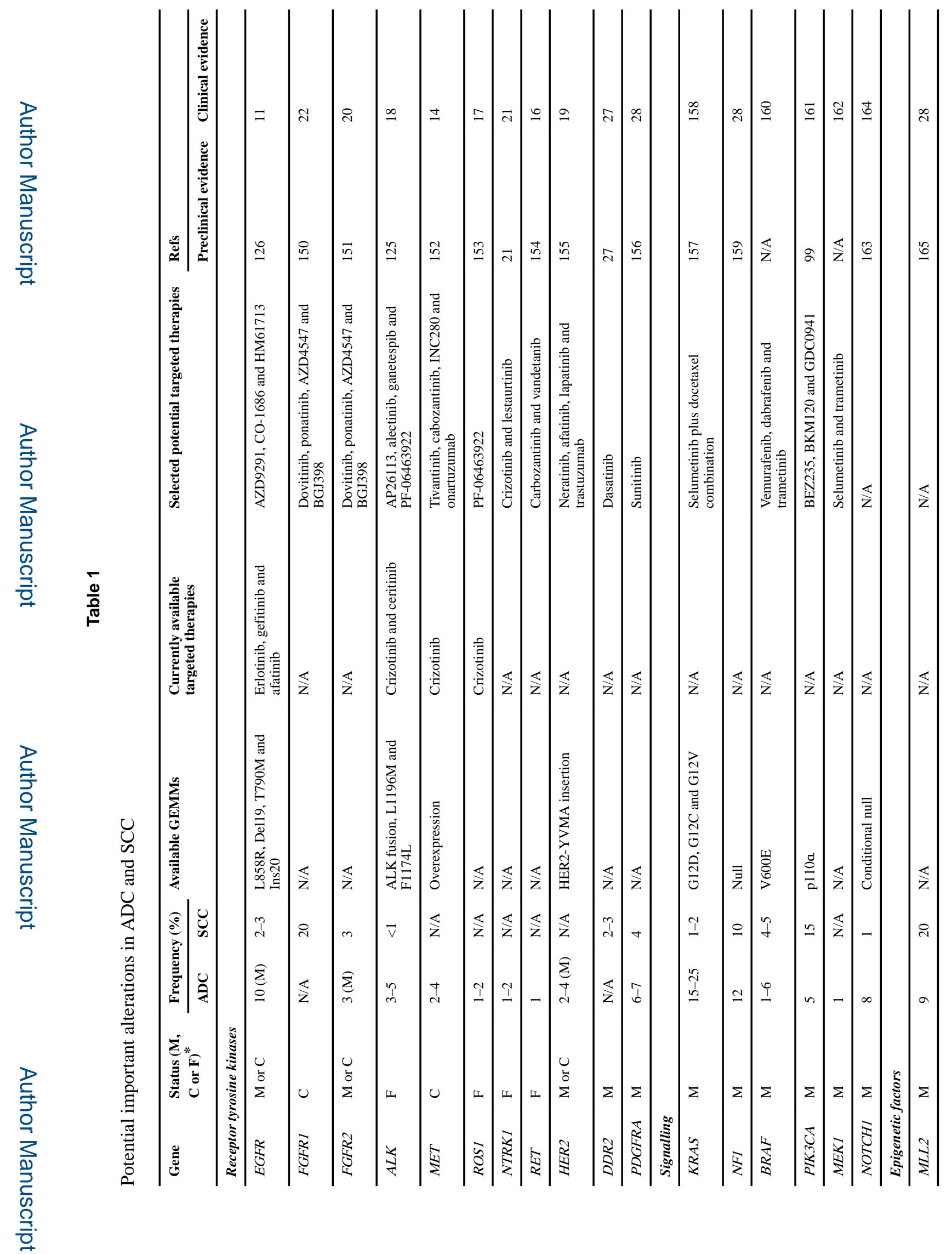

Nat Rev Cancer. Author manuscript; available in PMC 2017 December 04. 
Chen et al.

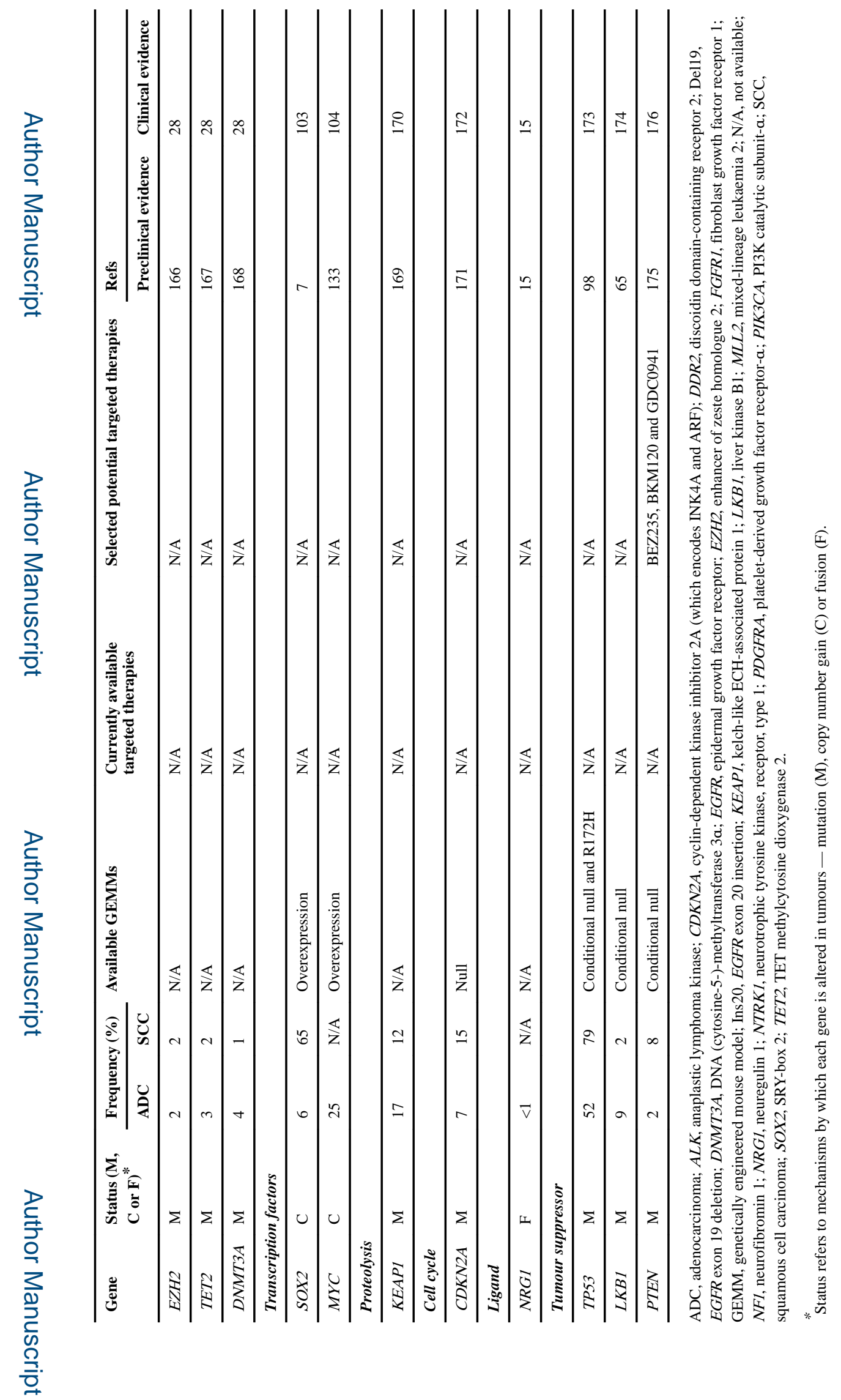

Nat Rev Cancer. Author manuscript; available in PMC 2017 December 04. 